\title{
All-trans retinoic acid synergizes with topotecan to suppress AML cells via promoting RARa-mediated DNA damage
}

\author{
Zhifei Xư ${ }^{\dagger}$ JinJin Shao ${ }^{\dagger}$ Lin Li, Xueming Peng, Min Chen, Guanqun Li, Hao Yan, Bo Yang, Peihua Luo* \\ and Qiaojun $\mathrm{He}^{*}$
}

\begin{abstract}
Background: Chemotherapy is the only therapy option for the majority of AML patients, however, there are several limitations for this treatment. Our aim was to find a new chemotherapy strategy that is more effective and less toxic.

Methods: MTT assays and a xenograft mouse model were employed to evaluate the synergistic activity of all-trans retinoic acid (ATRA) combined with topotecan (TPT). Drug-induced DNA damage and apoptosis were determined by flow cytometry analysis with PI and DAPI staining, the comet assay and Western blots. Short hairpin RNA (shRNA) and a RARa plasmid were used to determine whether RARa expression influenced DNA damage and apoptosis.

Results: We found that ATRA exhibited synergistic activity in combination with Topotecan in AML cells, and the enhanced apoptosis induced by Topotecan plus ATRA resulted from caspase pathway activation. Mechanistically, ATRA dramatically down regulated RARa protein levels and led to more DNA damage and ultimately resulted in the synergism of these two agents. In addition, the increased antitumor efficacy of Topotecan combined with ATRA was further validated in the HL60 xenograft mouse model.
\end{abstract}

Conclusions: Our data demonstrated, for the first time, that the combination of TPT and ATRA showed potential benefits in AML, providing a novel insight into clinical treatment strategies.

Keywords: AML, Topotecan, All-trans retinoic acid, Apoptosis, DNA damage, RARa

\section{Background}

Acute myeloid leukemia (AML) is the most common acute leukemia worldwide and has high mortality rates, the overall median survival for patients with AML is 6.5 months due to limited treatment choices $[1,2]$. The current treatment options for patients with AML are bone marrow transplants, radiofrequency ablation and chemotherapy [3]. Bone marrow transplants are only curative for a small percentage of matching patients [4]. Meanwhile, the efficacy or response rate of radiofrequency ablation in advanced AML is pretty low [5].

\footnotetext{
* Correspondence: peihualuo@zju.edu.cn; qiaojunhe@zju.edu.cn

${ }^{\dagger}$ Equal contributors

Zhejiang Province Key Laboratory of Anti-Cancer Drug Research, Institute of Pharmacology and Toxicology, College of Pharmaceutical Sciences, Zhejiang University, 866 Yuhangtang Road, Zijingang Campus, Hangzhou 310058, Zhejiang, People's Republic of China
}

(C) 2015 Xu et al. Open Access This article is distributed under the terms of the Creative Commons Attribution 4.0 International License (http://creativecommons.org/licenses/by/4.0/), which permits unrestricted use, distribution, and reproduction in any medium, provided you give appropriate credit to the original author(s) and the source, provide a link to the Creative Commons license, and indicate if changes were made. The Creative Commons Public Domain Dedication waiver (http://creativecommons.org/publicdomain/zero/1.0/) applies to the data made available in this article, unless otherwise stated.

Chemotherapy, the only or necessary choice for most AML patients, is often limited by toxicities [6]. Therefore, it is critical to discover effective drug treatments for AML patients.

Topotecan [10-hydroxy-9-dimethylaminomethyl-(S)camptothecin] (TPT), a semisynthetic topoisomerase 1 inhibitor derived from camptothecin (CPT), is active in patients with different types of solid tumors [7-10]. TPT forms a covalent complex between Topoisomerase 1 and DNA, also called the cleavage complex, resulting in DNA damage during cell replication and transcription, ultimately leading to apoptosis $[11,12]$. This mechanism is being investigated for salvage and front-line therapy in AML patients combined with other medicines, such as etoposide, cytarabine, and cyclophosphamide [13-17]. Unfortunately, clinical studies have shown that the 
activity of these therapies in AML is also limited due to their dose-dependent toxicity. Therefore, discovering potential drugs synergistic to the anticancer activity of TPT that do not enhance its toxicity is critical.

All-trans retinoic acid (ATRA) is a derivative of vitamin A that has good efficacy and has shown less side effects in APL during clinical observations [18]. Experimental studies showed that ATRA treatment in AML affects leukemic cell morphology, regulation of cell cycle progression and apoptosis by activating nuclear receptors, including retinoic acid receptors (RAR types $\alpha, \beta, \gamma$ ) and retinoid X receptors (RXR types $\alpha, \beta, \gamma$ ) [19]. Therefore, ATRA is the most promising agent to enhance the antitumor activity of TPT in AML.

In this study, we identified that the combination of TPT with ATRA have synergistic effects to AML in vitro and in vivo. Our study provides molecular insights for apoptosis involving TPT and ATRA by demonstrating that ATRA helps TPT cause serious DNA damage leading the AML cells HL60 to apoptosis, and RAR $\alpha$ is involved in this process. Our results indicate that the TPT-ATRA combination may be a promising alternative chemotherapeutic strategy for AML.

\section{Methods}

\section{Reagents}

ATRA (cat \# R2625) was obtained from Sigma (St Louis, $\mathrm{MO}$, USA) and stored in ethanol at $-40{ }^{\circ} \mathrm{C}$. TPT, with more than $99 \%$ purity, is synthesized by professor Wei Lu (East China Normal University) and dissolved in dimethylsulfoxide (DMSO) as stock solution at $10 \mathrm{mM}$. The stock solution was kept frozen in aliquot at $-40{ }^{\circ} \mathrm{C}$ and thawed immediately prior to each experiment.

\section{Cell line and cell culture}

HL60, NB4 and U937, the human acute myelocytic leukemia cell lines, were obtained from ATCC, and they were maintained in complete media (RPMI-1640 medium (Gibco, Grand Island, NY, USA) supplemented with $10 \%$ heat-inactivated fetal bovine serum (FBS) plus penicillin $(100$ units $/ \mathrm{ml})$ and streptomycin $(100 \mathrm{ug} / \mathrm{ml}))$ at $37{ }^{\circ} \mathrm{C}$ in $5 \% \mathrm{CO}_{2}$.

\section{Cell Proliferation assay in vitro}

The cytotoxic activity was detected by MTT assay. After Cells were cultured in 96-well plates at $4 \times 10^{3}$ cells/well, and allowed to proliferate to confluence in $5 \% \mathrm{CO}_{2}$ incubator at $37^{\circ} \mathrm{C}$ overnight; exposed to different concentrations of TPT, ATRA or TPT combined with ATRA for $48 \mathrm{~h}$. Cells were then incubated with MTT $5 \mathrm{mg} / \mathrm{ml}$ (Sigma, USA) for $4 \mathrm{~h}$. A quantity of $100 \mathrm{ml}$ of DMSO (dimethyl sulfoxide) was added to each well after removing the supernatant. Cell viability was obtained by measuring the absorbance on a Multiskan Spectrum
(Thermo Electron Corporation, Marietta, Ohio) at $570 \mathrm{~nm}$.

The growth inhibition was calculated according to the following formula: the Growth Inhibition Ratio $(I R \%)=[$ (the absorbance of blank control group - the absorbance of experimental group)/the absorbance of blank control group] $\times 100 \%$.

\section{PI staining for flow cytometry}

The sub-G1 analysis after PI staining was employed to assess the apoptosis. HL60 cells $\left(10^{5} / \mathrm{ml}\right)$ were seeded into 6well plates and exposed to either or both of TPT and ATRA for $48 \mathrm{~h}$. Cells were then harvested and washed with ice-cold PBS, fixed with precooled $75 \%$ ethanol at $-20{ }^{\circ} \mathrm{C}$ overnight. Cells were washed, and resuspended in $500 \mu \mathrm{l}$ of PBS containing $100 \mu \mathrm{g} / \mathrm{ml}$ RNase (Amersco, Solon, OH, USA), then incubated at $37{ }^{\circ} \mathrm{C}$ for $30 \mathrm{~min}$. After incubation, the cells were stained with $200 \mu \mathrm{g} / \mathrm{ml}$ propidium iodide (PI, Sigma, St Louis, MO, USA) in the dark at room temperature for $30 \mathrm{~min}$. For each sample, at least $2 \times 10^{4}$ cells should be analyzed using an FACS-Calibur cytometer (BD Biosciences, Sanjose, CA), and the data were analyzed using cellquest software (BD biosciences).

JC-1 stain for mitochondrial membrane potential $\left(\triangle \Psi_{\mathrm{m}}\right)$ HL60 cells were inoculated into 6-well plates $(150,000 /$ well) for $24 \mathrm{~h}$ growth. After stabilisation for $24 \mathrm{~h}$ HL60 were treated with TPT, ATRA or both for $24 \mathrm{~h}$ and then harvested. Wash twice with PBS and suspend in $500 \mu \mathrm{l}$ PBS with $2.5 \mu \mathrm{l} \mathrm{JC}-1(20 \mu \mathrm{g} / \mathrm{ml})$. Keep the samples in $37{ }^{\circ} \mathrm{C}, 5 \% \mathrm{CO} 2$, for $30 \mathrm{~min}$. Then analyze immediatly with the flow cytometer, typically equipped with a $488 \mathrm{~nm}$ argon laser. JC-1 is a cationic dye that exhibits potential-dependent accumulation in mitochondria, indicated by a fluorescence emission shift from green $(525 \pm$ $10 \mathrm{~nm})$ to red $(610 \pm 10 \mathrm{~nm})$. Samples $(1 \times 104 \mathrm{cells} / \mathrm{sam}$ ple) were analyzed by FACS Calibur (Becton Dickinson, CA, USA).

\section{Immunofluorescence}

For morphological studies, exponentially growing cells were cultured in $3 \times 10^{5} /$ well in 6 -well plates and treated with TPT, ATRA or both for $48 \mathrm{~h}$. The cells were washed with PBS, fixed with $0.1 \%$ Triton X-100 for $15 \mathrm{~min}$ at room temperature, stained with 4,6-dianidino2-phenylindole dihydrochloride (DAPI, $2.0 \mu \mathrm{g} / \mathrm{ml}$, Sigma) for another $15 \mathrm{~min}$. Morphological changes of cell nucleus were examined in a fluorescence microscope, and they were photographed using a digital color camera DFC 300 FX (Leica, Wetzlar, Germany).

\section{Western blot analysis}

The protein samples were prepared as described previously. Briefly, proteins of HL60 cells were extracted in 
lysis buffer $(150.0 \mathrm{mM} \mathrm{NaCl}, 50 \mathrm{mM}$ Tris- $\mathrm{HCl}, 1 \mathrm{mM}$ EDTA, $0.1 \%$ SDS, $0.5 \%$ dexoycholic acid, $0.02 \%$ sodium azide, $1 \% \mathrm{NP}-40,2.0 \mu \mathrm{g} / \mathrm{ml}$ aprotinin, $1 \mathrm{mM}$ phenylmethylsulfonylfluoride). The lysates were centrifuged at $10^{4} \times \mathrm{g}$ for $15 \mathrm{~min}$ at $4{ }^{\circ} \mathrm{C}$. Equivalent amounts of proteins were analyzed by $8 \%-15 \%$ SDS-PAGE and electroblotted onto PVDF membranes (Millipore Corporation, Billerica, Massachusetts), and probed with primary antibodies. Appropriate antibodies to anti-caspase-3, anti-poly-ADP-ribose polymerase (PARP), anti-Bax, anti-chk1, anti-chk2 and anti- $\beta$-actin from Santa Cruz Biotechnology (Santa Cruz, CA, USA); anti-Bcl-2, anti-p-chk1, anti-p-chk2, and anti- $\gamma$-H2AX from Cell Signaling Technology (Beverly, MA, USA); and anti-Cytochrome $C$ from Cell Signaling Technology (Boston, MA, USA) were used. The proteins were visualized with peroxidase-coupled secondary antibodies (Southern Biotech, Birmingham, UK), and using the enhanced chemiluminescence detection system (Biological Industries, Beit Haemek, Israel) for detection.

\section{Alkaline comet assay}

The alkaline comet assay, also called alkaline single-cell gel electrophoresis assay, was done according to the procedure of Huang et al. [20]. with minor modification. Briefly, drug-treated HL60 cells $\left(10^{5} / \mathrm{ml}\right)$ were pelleted and resuspended in ice-cold PBS. A $50 \mu \mathrm{l}$ sample of resuspended cells was the mixed with an equal volume of prewarmed $1 \%$ low-melting point agarose. The cellagarose mixture was placed on a slide precoated with $0.5 \%$ agarose and spread gently with a coverslip. After $10 \mathrm{~min}$ at $4{ }^{\circ} \mathrm{C}$, immersed the slides in precooled lysis buffer $\left[2.5 \mathrm{M} \mathrm{NaCl}, 100 \mathrm{mM} \mathrm{Na} \mathrm{N}_{2}\right.$ EDTA, and $10 \mathrm{mM}$ Tris- $\mathrm{HCl}$ (pH 10)] for $90 \mathrm{~min}$ in the dark. After soaking with electrophoresis buffer $(0.3 \mathrm{M} \mathrm{NaOH}$ and $1 \mathrm{mM}$ EDTA) for $20 \mathrm{~min}$, the slides were subjected to electrophoresis for $15 \mathrm{~min}$. The cells were stained with DAPI at last, and individual cells were observed in a fluorescence microscope, and photographed by DFC 300 FX (Leica, Wetzlar, Germany).

\section{Retroviral infection}

To prepare the retroviruses, 293FT cells were plated at $6-8 \times 10^{5}$ cells per well in 6 -well plates coated with $20 \mu \mathrm{g} \mathrm{ml}^{-1}$ of poly-ornithine. Twenty-four hours after plating, the cells were transfected with RAR $\alpha$ shRNA plasmid, along with pUMVC and pCMV-VSV-G plasmids at the ratio of $2.125 \mu \mathrm{g}$ of plasmid DNA to $5 \mu \mathrm{l}$ of Lipofectamine 2000 in $500 \mu \mathrm{l}$ Opti-MEM (both from Invitrogen). The ratio of shRNA:Pumvc: pCMV-VSV-G was 8:8:1. Twenty-four hours after transfection, the DMEM media was replaced with fibroblast (MEME) media. The next day the culture media containing the retroviruses was harvested and mixed 1:1 with $0.6 \mu \mathrm{g} \mathrm{ml}^{-1}$ polybrene (Sigma-Aldrich). The cell debris in the mixtures was removed using $0.45 \mu \mathrm{m}$ low-protein-binding filters (Nalgene). The HL60 cells were plated at $2.5 \times 10^{5}$ cells per well in 6-well plates one day before infection with the retroviruses. The retrovirus solution was mixed with the cells for $6 \mathrm{~h}$, then certain amount of fresh 1640 media was added for reducing the toxcity of polybrene. After infection of $24 \mathrm{~h}$, cells were immediately transferred to complete RPMI-1640 supplemented with $10 \%$ fetal bovine serum and cultured at $37{ }^{\circ} \mathrm{C}$ until analysis.

\section{Lentivirus transduction}

With Lipofectamine 2000, vesicular stomatitis viruspseudo-typed vectors were produced by transient cotransfection of 293FT cells with $10 \mu \mathrm{g}$ of the expression construct (pccl, or pccl-RARa), $10 \mu \mathrm{g}$ of the $\mathrm{pR} \triangle 8.9$ packaging plasmid, and $2 \mu \mathrm{g}$ of the pMD.G envelope plasmid. Sodium pyruvate (Invitrogen) induction was performed according to the manufacturer's instructions. After $72 \mathrm{~h}$, the viral supernatants were harvested, centrifuged (800 g, $15 \mathrm{~min}$ ), and filtered. After determination of the titer of the vector supernatants, HL60 cells were transduced with the indicated lentivirus particles (multiplicity of infection of $1: 1$ ) in the presence of $8 \mu \mathrm{gmL}^{-1}$ polybrene. A second cycle of transduction was performed $24 \mathrm{~h}$ later with new viral supernatants in the presence of fresh polybrene. After $24 \mathrm{~h}$, the cells were washed and cultured in fresh medium.

\section{Animals and antitumor activity in vivo}

Male immune-deficient nude mice at 4 weeks of age (National Rodent Laboratory Animal Resource, Shanghai Branch, China) were maintained in pathogen-free conditions with irradiated chow. Animals were unilaterally, subcutaneously (s.c.) injected with $5 \times 10^{6}$ HL60 cells/ tumor in $0.1 \mathrm{ml}$ Matrigel (Collaborative Biomedical Products, Bedford, MA). When HL60 cells formed palpable tumors, mice were divided randomly into 4 groups receiving control $(\mathrm{n}=3)$, TPT alone $(\mathrm{n}=3)$, ATRA alone $(n=3)$ or combination of both TPT and ATRA $(n=3)$. ATRA $(5 \mathrm{mg} / \mathrm{kg}$ ) was dissolved in corn oil and given to mice by gavage and TPT $(2 \mathrm{mg} / \mathrm{kg})$ was given to mice by intraperitoneal injection every two days of the experimental period. Control group received vehicle $(0.5 \%$ methylcellulose, $0.2 \%$ Tween 80 and $99.3 \%$ DDW, i.g. administration) everyday and $0.9 \%$ saline solution by intraperitoneal injection every two days of the experimental period. Body weight and tumors were measured every two days. Tumor sizes were calculated by the formula: (length $\times$ width $\times$ width)/2, and the length, width and height is in millimeters. At the end of the experiment, animals were sacrificed by $\mathrm{CO}_{2}$ asphyxiation and tumor weights were measured after their careful resection. Tumor tissue was collected for analysis. The individual relative tumor volume (RTV) was calculated 
according to the following formula: $\mathrm{RTV}=\mathrm{V}_{\mathrm{N}} / \mathrm{V}_{0}$, where $\mathrm{V}_{\mathrm{N}}$ is the tumor volume on day $\mathrm{n}$ and $\mathrm{V}_{0}$ is the tumor volume on day of initial treatment. Therapeutic effects of treatment were expressed in terms of $\mathrm{T} / \mathrm{C} \%$ using the calculation formula $\mathrm{T} / \mathrm{C}(\%)=$ mean RTV of the treated group/mean RTV of the control group $\times 100 \%$ [21]. All procedures were in accordance with the ethical standards of, and the protocols were approved by, the Animal Ethical and Welfare Committee (AEWC), Center for Drug Safety Evaluation and Research, Zhejiang University.

\section{TUNEL assay}

To evaluate the apoptotic response in tumor tissue, we applied terminal deoxynucleotidyl transferase (TdT)-mediated dUTP-digoxigenin nick-end labeling (TUNEL) technique, to formalin-fixed tumor samples in paraffin blocks, using the one-step TUNEL apoptosis assay kit produced by Beyotime Institute of Biotechnology in China. The sections $(4-5 \mu \mathrm{m})$ mounted on glass slides were deparaffinized, rehydrated thoursough graded alcohols to water, treated with $20 \mu \mathrm{g} / \mathrm{ml}$ proteinase $\mathrm{K}\left(37{ }^{\circ} \mathrm{C}\right.$, $20 \mathrm{~min}$ ) and then washed in $1 \times$ Tris buffer. TUNEL assay was then performed according to the manufacturer's instructions.

\section{Statistical analysis}

Data were presented as mean \pm SD for thoursee separate experiments. Comparions between groups were made with unpaired Student's two-tailed $t$ test and $P<0.05$ was considered statistically significant.

\section{Results}

\section{TPT and ATRA synergistically induce a cytotoxic effect in AML cells}

To evaluate the potential synergy between ATRA and the Topoisomerase1 inhibitor TPT, cells (HL60, NB4 and U937) were exposed for $48 \mathrm{~h}$ to increasing concentrations of TPT $(0,20,40,60,80 \mathrm{nM})$ alone or in combination with ATRA at a concentration that reduces cell viability according to data from preclinical research and our laboratory. As shown in Fig. 1b, a synergistic effect was observed in ATRA combined with lower concentrations of TPT (20 nM and $40 \mathrm{nM})$. However, as the concentration of TPT increased the cytotoxicity appeared much more severe with no significant differences between the TPT group ( $60 \mathrm{nM}$ and $80 \mathrm{nM}$ ) and the TPT plus ATRA group. To validate the combination efficiency, we calculated the Coefficient of Drug Interaction (CDI) values, which are used to quantify drug synergism. $\mathrm{CDI}$ values less than, equal to or greater than 1 indicate that the drugs are synergistic, additive or antagonistic, respectively. CDI values less than 0.7 indicate that the drugs are significantly synergistic. The CDI values for different ratio concentrations of ATRA and TPT were calculated. As shown in Fig. 1c, the combination of ATRA and TPT had apparent synergism in HL60, NB4 and U937 cells with CI values $<1$. Cells treated with the combination of TPT and ATRA showed cell morphology changes and had more cell debris appearing compared to TPT or ATRA groups in Fig. 1d. Thus, we demonstrated that ATRA has synergistic cytotoxicity with TPT in AML cells.

\section{ATRA enhances TPT-triggered caspase-dependent apoptosis in vitro}

To further explore the mechanisms of enhanced antitumor activity caused by the combination of TPT and ATRA, we examined their effects on apoptosis and caspase signaling pathways. Flow cytometry analysis after PI staining was used first to identify the apoptosis-inducing effects. As shown in Fig. 2a, PI staining for sub-G1 content analysis was used to characterize the apoptosis process in HL60 cells treated with TPT (20 nM and $40 \mathrm{nM}), 1 \mu \mathrm{M}$ ATRA or the combination for $48 \mathrm{~h}$. Exposure to ATRA drove a few cells to apoptosis, and the content of sub-G1 was close to the control group (approximately $2 \%$ ). However, using ATRA with TPT generated more apoptotic cells compared to TPT treatment alone. Then, DAPI staining further showed that the combination of $1 \mu \mathrm{M}$ ATRA and TPT for $48 \mathrm{~h}$ triggered more apoptosis compared to the treatment of either drug alone. As Fig. 2c depicts, apoptotic bodies were seldom found in control cells and the monotreated ATRA cells. However, apoptotic bodies appeared in cells exposed to TPT. Adding ATRA showed more apoptotic bodies with the accompanied nuclei shrinking and disintegrating.

To explore the signaling mechanism for TPT and ATRA synergistic induction of apoptosis, we investigated the expression levels of apoptosis-related proteins, such as caspase-3 and PARP, as shown in Fig. 2d, using Western blot analysis. Incubation with TPT at the indicated concentrations (20 $\mathrm{nM}$ and $40 \mathrm{nM}$ ) combined with ATRA $(1 \mu \mathrm{M})$ for $24 \mathrm{~h}$ caused significant cleavage of PARP compared to the monotreated cells. Pro-caspase3, upstream PARP [22], was cleaved more severely with the combination of $40 \mathrm{nM}$ TPT and ATRA. Then, we used Z-VAD-FMK, the pan-caspase inhibitor, to further confirm the mechanism previously mentioned. As shown in Fig. 2e, the apoptosis induced by the combination treatment was almost reversed in the presence of $\mathrm{Z}$ VAD-FMK, as detected by the PI (sub-G1) staining assay. All of these results indicated that caspase involvement led to apoptosis triggered by TPT plus ATRA. In summary, our results demonstrated that a combination treatment of TPT and ATRA triggers apoptosis via caspase cascades leading to increased cell death. 


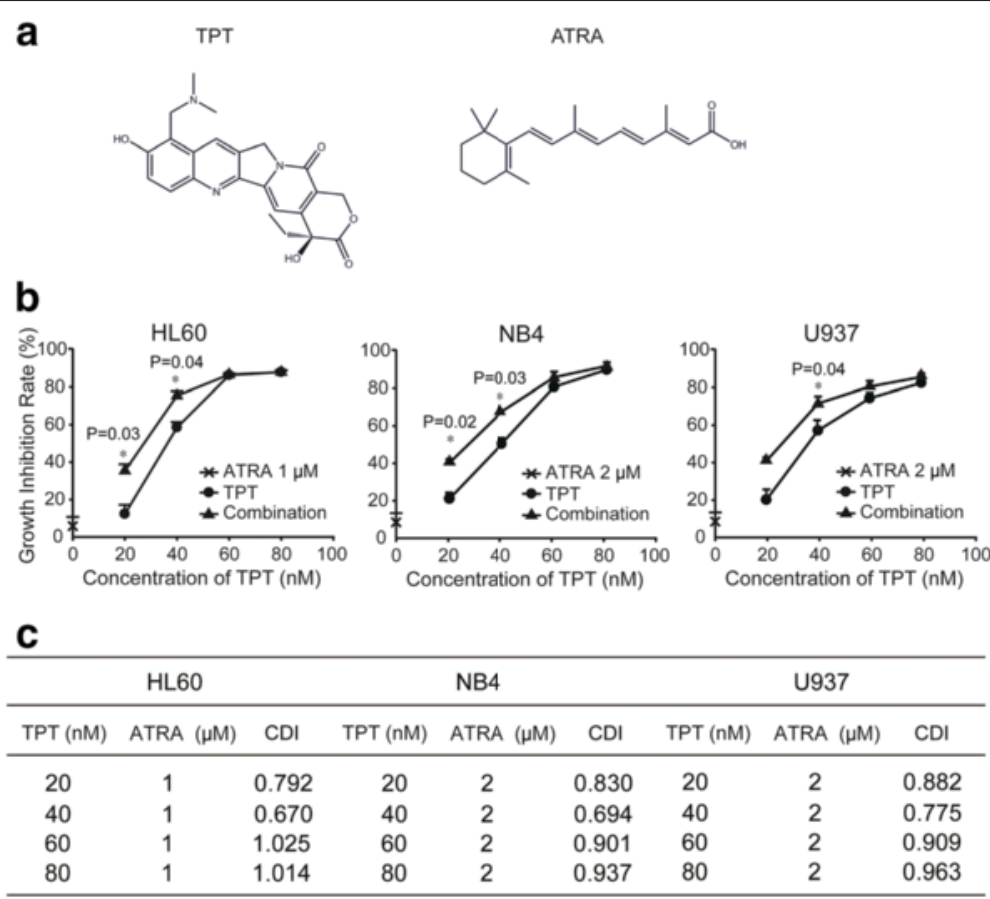

d
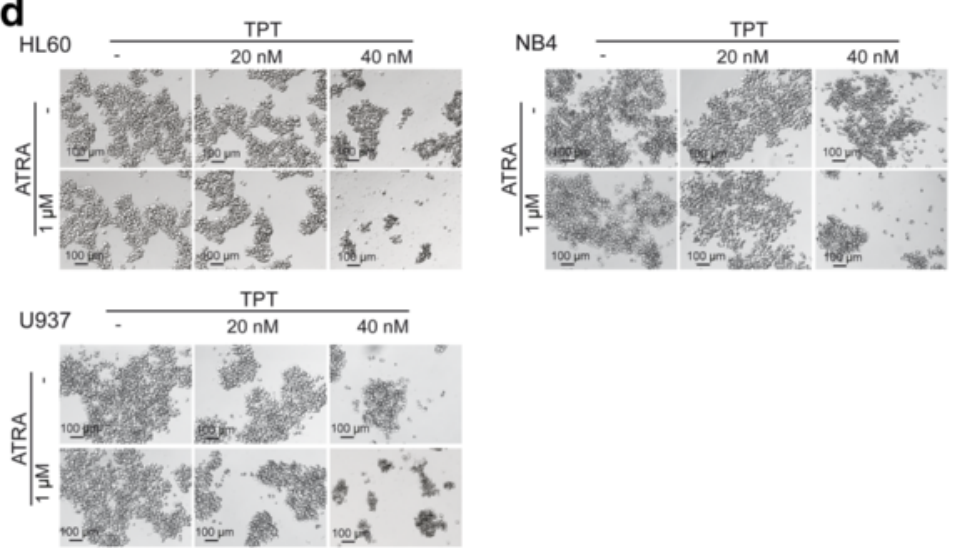

Fig. 1 Combinational cytotoxicity of Topotecan (TPT) and ATRA. a Chemical structures of TPT and ATRA. b Combination of TPT and ATRA induce cytotoxicity in HL60, NB4 and U937 cells. $4 \times 103$ cells per well were cultured in 96-well plates and incubated with the indicated concentrations of TPT and ATRA for $48 \mathrm{~h}$. Mean \pm SD from three independent experiments. *: Compared to TPT group, $p<0.05$. c CDI values at different ratio concentrations of TPT and ATRA (1 or $2 \mu \mathrm{M})$ were calculated by the proliferation inhibition rates. Each study was performed three times and the error bars represent the SD around the mean. $\mathbf{d}$ Cell morphology change was observed by microscope (magnification 200x) after combination of TPT and ATRA

\section{Mitochondrial damage was involved in caspase-dependent apoptosis}

Mitochondrial damage in response to cellular conditions is an important constituent of apoptosis, and the mitochondrial membrane potential is one of the most remarkable events [23]. In order to explore the role of mitochondrial damage in apoptosis induced by a combination treatment of TPT and ATRA, JC-1 staining and flow cytometry were conducted after a $24 \mathrm{~h}$ treatment. The results showed that cells treated with the combined
TPT and ATRA induced the loss of mitochondrial membrane potential compared to TPT or ATRA groups in Fig. 3a-b. The oncoprotein Bcl-2 is an antagonist of the mitochondrial pathway for apoptosis [24]. $\mathrm{BAX}$ is a member of the Bcl-2 gene family that forms a heterodimer with bcl-2 and functions as an apoptotic activator [25]. As shown in Fig. 3c, Western blot analysis revealed that bcl- 2 is down-regulated and bax is up-regulated in HL60 cells treated with TPT and ATRA together. Cytochrome C, which normally 

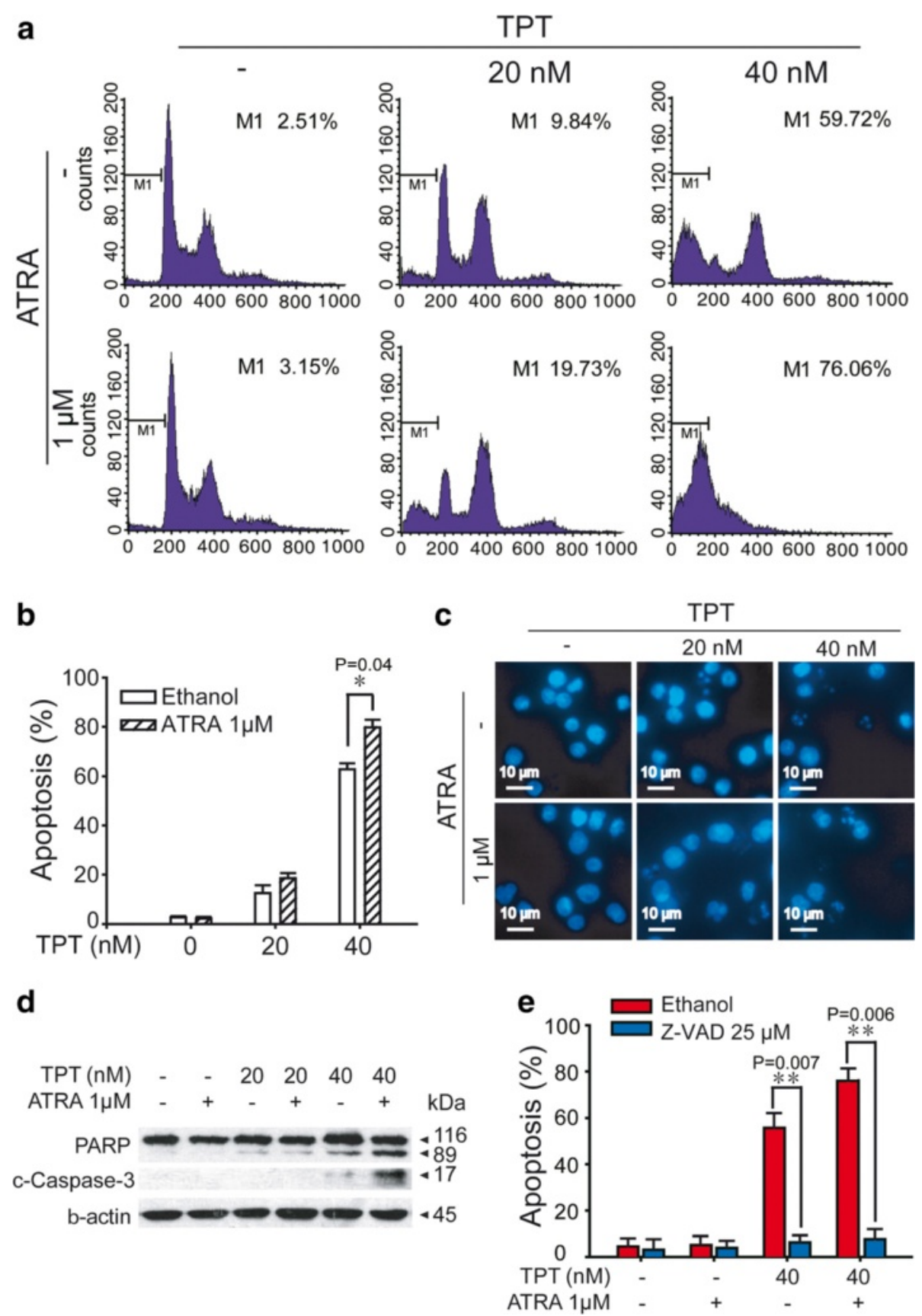

Fig. 2 Combination of TPT and ATRA induce apoptosis in HL60 cells. $\mathbf{a}$ and $\mathbf{b}$ Effects of ATRA in combination with TPT and ATRA on cell cycle kinetics of HL60 cells. Cell cycle analysis was done after propidium iodide (PI) staining on cells exposed to TPT or ATRA either alone or in combination as indicated. *: Compared to $40 \mathrm{nM}$ TPT group, $\mathrm{p}<0.05$. c Morphology of apoptotic bodies in HL60 cells treated with TPT, ATRA, or combination for $48 \mathrm{~h}$. Cells were stained with DAPI and observed by fluorescence microscope (magnification 200X). $\mathbf{d}$ HL60 cells were exposed to TPT, ATRA, or combination for $24 \mathrm{~h}$, after which, protein extracts were immunoblotted with specified antibodies for PARP and cleaved-caspase-3. e. HL60 cells were pretreated with $25 \mu \mathrm{M}$ Z-VAD-FMK (the pan-caspase inhibitor) for $1 \mathrm{~h}$ and treated with TPT and/or ATRA for $24 \mathrm{~h}$. The cells were analysed on flow cytometry. *: Compared to ethanol group, $p<0.05$. The experiments were performed three times independently, and the error bars represent the SD around the mean

resides exclusively in the intermembrane space of mitochondria, is released into the cytosol during apoptosis. Cytochrome $\mathrm{C}$ release from mitochondria to the cytoplasm was shown to be up-regulated in HL60 cells treated with TPT and ATRA together, as depicted in Fig. 3c. These data suggest that the combination treatment of TPT and ATRA induced mitochondrial associated-apoptosis. 

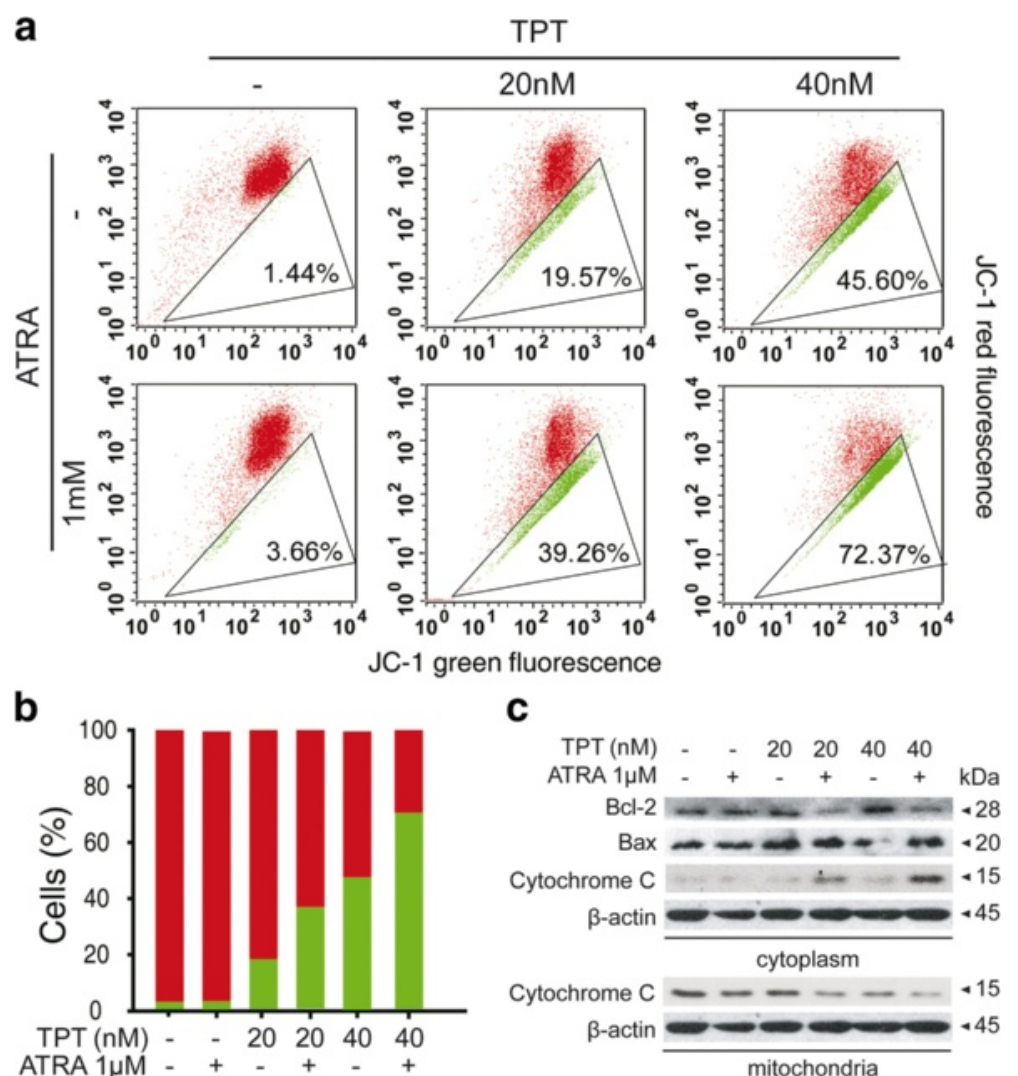

Fig. 3 Mitochondrial damage was involved in caspase-dependent apoptosis. a and $\mathbf{b}$ Effects of TPT, ATRA, or combination for $24 \mathrm{~h}$ on loss of mitochondrial membrane potential in HL60 cells were detected by flow cytometry after JC-1 staining. $\mathbf{b}$ The rates of red to green after HL60 Cells treated with TPT, ATRA, or combination for 24 h. c Effects of TPT, ATRA, or combination on Bcl-2, Bax and Cytochrome C protein expression were analyzed by western blot

Induction of apoptosis mediated by the combined treatment of TPT and ATRA is correlated to enhanced DNA damage in AML cells

TPT is a cytotoxic drug that adheres Topoisomerase 1 to DNA, which inhibits the function of Topoisomerase 1 in DNA repair [12]. Trapped Topoisomerase 1 leads to single strand DNA breakage and then to cell death. We used the comet assay to determine if ATRA plays a role in TPT induced-DNA damage. The alkaline version detects both single-strand and double-strand breaks (DSBs), and the neutral version only detects doublestrand breaks [26, 27]. Exposure to different concentrations of TPT and ATRA for one hour showed obvious "comet tails" in two of the groups: the combination group and the positive control group for $200 \mathrm{nM}$ TPT. The other groups showed only obscure "halos" without clear directions (Fig. 4a). The results demonstrated that treatment with ATRA and TPT for one hour induced HL60 DNA damage with 200 nM TPT. However, neither treatments of $1 \mu \mathrm{M}$ ATRA or $40 \mathrm{nM}$ TPT had similar effects.
Because the "tails" were caused by single-strand or double-strand breaks, we next detected the level of phosphorylated-H2AX $(\gamma-\mathrm{H} 2 \mathrm{AX})$ in DNA DBSs that are accompanied by the elevation of $\gamma$-H2AX. Phosphorylation of histone $\mathrm{H} 2 \mathrm{AX}$ on serine 139 was one of the earliest cellular responses after the formation of DNA damage [28]. This phosphorylated form of H2AX (referred to as $\gamma$-H2AX) was used as a marker for the presence of DNA damages. AML cells, including HL60, NB4 and U937 cells, were incubated with TPT, ATRA, or both and proteins were collected at $1,3,6$, and $8 \mathrm{~h}$, respectively. As shown in Fig. 4b, $\gamma$-H2AX expression increased from a very low level to a high level, which demonstrated that only exposure to TPT and ATRA for eight hours induced DBSs. Therefore, the "comet tails" formed after one hour of drug treatment were caused by SSBs (Fig. 4c). TPT inhibits topoisomerase1 and causes single-strand DNA breaks, which inhibit DNA function and ultimately lead to cell death by generating doublestranded DNA breaks during DNA replication [29]. Furthermore, we examined p-Chk1 and p-Chk2 which are 

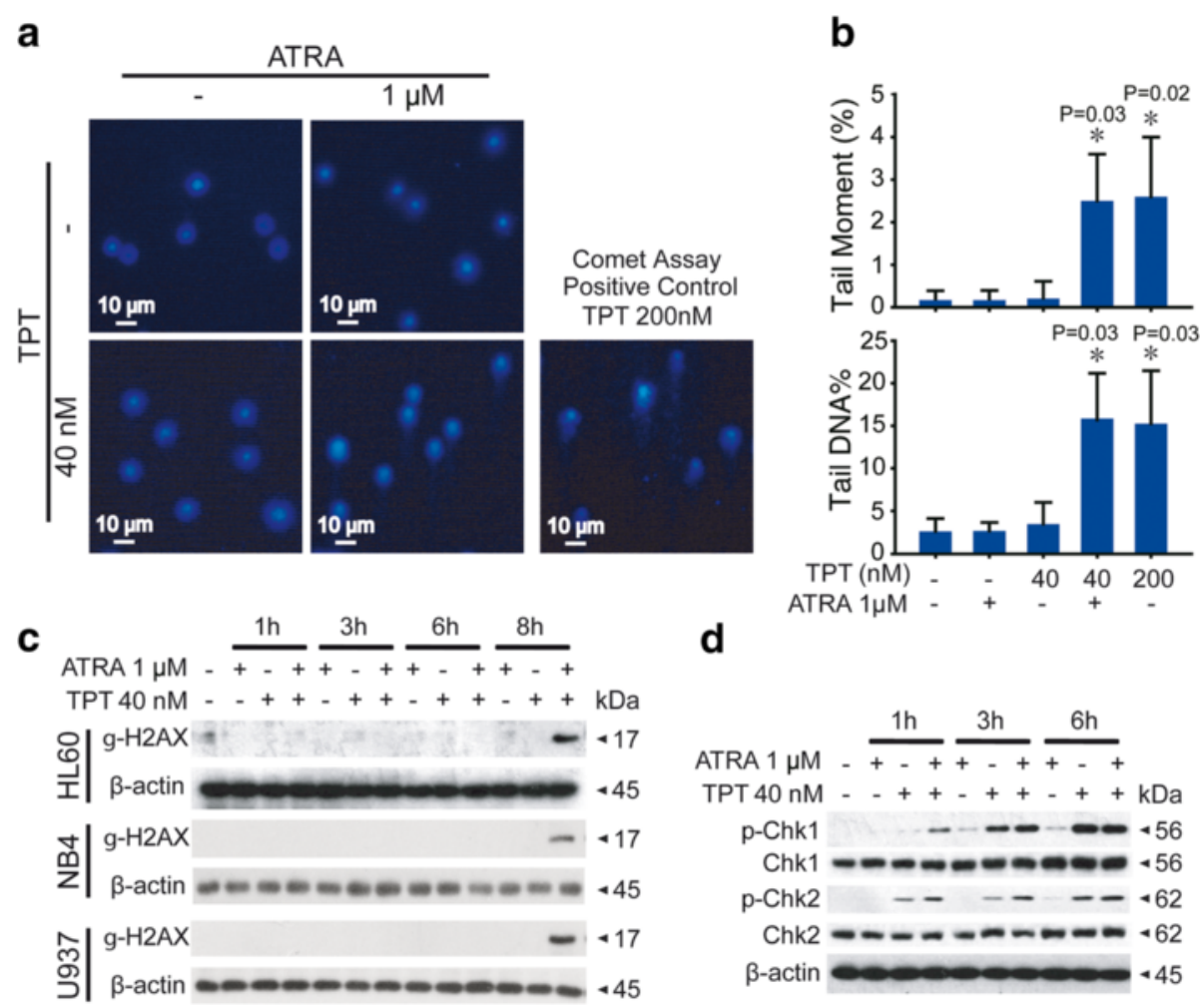

Fig. 4 ATRA synergistically induced DNA damage in combination with TPT. a and $\mathbf{b}$ HL60 cells were treated with or without 40 nM TPT or $1 \mu M$ ATRA for $1 \mathrm{~h}$. Alkaline comet assay was used for detection of single-strand breaks (SSBs). Representative comet images of each group were shown and 200nM TPT served as the positive control (magnification 200x). Tail Moment and Tail DNA\% were analysised the data from Comet assay. Each point represents mean \pm SD of three independent experiments. *Significantly different $(P<0.05)$ from the control, according to the Dunnett's test. c and $\mathbf{d}$ AML cells were exposed to TPT $(40 \mathrm{nM})$, ATRA $(1 \mu \mathrm{M})$, or in combination for indicated times, after that protein extracts were immunoblotted with specific antibodies of $\mathrm{Y}-\mathrm{H} 2 \mathrm{AX}$ (c), p-Chk1/2, Chk1/2 (d)

essential for responses to DNA damage [30]. These two checkpoint kinases were improved with the combination treatment of TPT and ATRA (Fig. 4d). These results indicated that ATRA and TPT synergistically induced apoptosis by causing serious DNA damage.

\section{RARa was involved in TPT-induced DNA damage}

RAR $\alpha$, the main target of ATRA, plays an important role in ATRA-therapies. Previous data has shown that ATRA elevates the activity of proteasomes leading to RAR $\alpha$ protein degradation by the ubiquitin-proteasome pathway [31, 32]. We found similar results for the ATRA treatment with prolonged time (Fig. 5a). Interestingly, the combination of ATRA and TPT downregulates RAR $\alpha$. To explore the role of RAR $\alpha$ in this combination therapy, retroviral shRNA was used to knockdown the RAR $\alpha$ expression levels in HL60 cells (Fig. 5b). Two days later, the cells were incubated with TPT for $24 \mathrm{~h}$ before PI staining and flow cytometry to detect cell apoptosis. Figure $5 c-d$ shows that treating with TPT for the same amount of time leads to cells with lower expression of RAR $\alpha$ and higher apoptosis percentages than in normal cells. From the comparisons between the control group and RAR $\alpha$-knockdown group, we concluded that low levels of RAR $\alpha$ proteins are beneficial for TPT-induced apoptosis.

To determine whether RAR $\alpha$ influences TPT-induced apoptosis through the DNA damage signaling pathway, we examined the related protein $\gamma-\mathrm{H} 2 \mathrm{AX}$. Increasing phosphorylation of H2AX was observed in Western blots for cells with low RAR $\alpha$ expression in the combination therapy group (Fig. 5e). To further confirm the role of RAR $\alpha$ in DNA damage, lentivirus transduction was used to overexpress RAR $\alpha$ in HL60 cells. Figure $5 f$ shows that the increasing phosphorylation of $\mathrm{H} 2 \mathrm{AX}$ was reversed in the RAR $\alpha$-overexpression group, and this observation demonstrated that the downregulation of RAR $\alpha$ may be a key factor for the accumulation of DNA damage and apoptosis.

\section{Synergistic antitumor efficacy of TPT and ATRA in HL60 xenografts}

In light of the in vitro synergistic effect of TPT and ATRA, we studied the in vivo anticancer activity of the combination therapy in nude mice bearing HL60 xenografts as described in the Materials and Methods. 
a

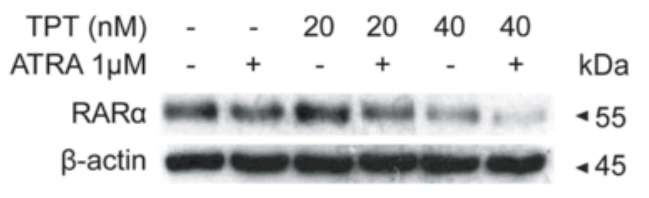

b

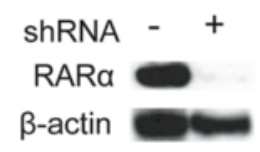

C

TPT
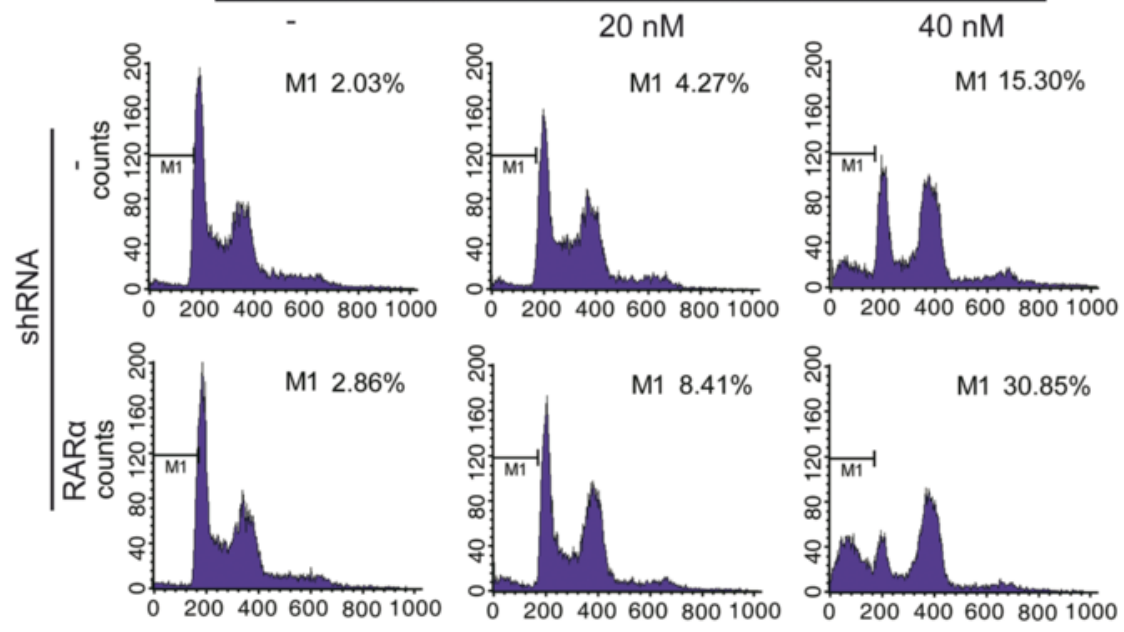

d

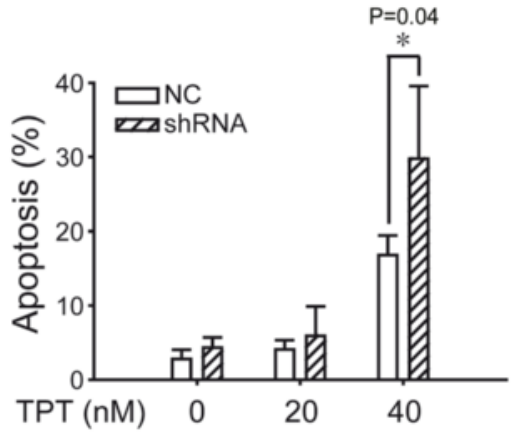

f

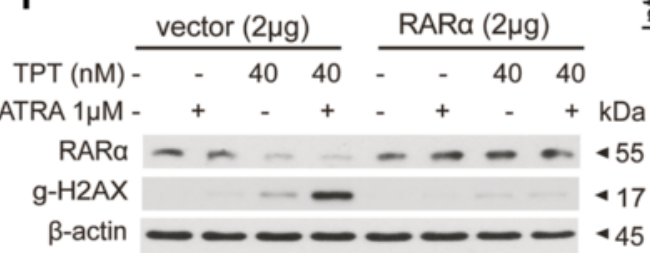

e
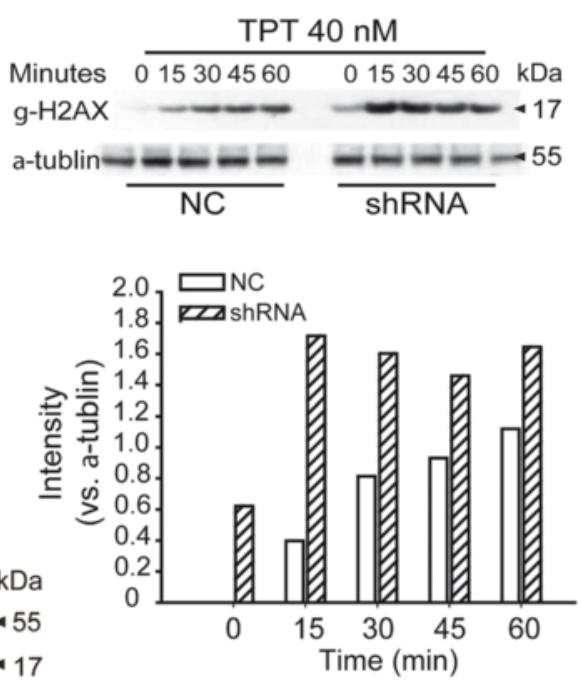

Fig. 5 RARa participated in synergistic induction of apoptosis by TPT and ATRA treatment. a After incubation with TPT (40 nM), ATRA (1 $\mu$ M), or combination for $24 \mathrm{~h}$, the lysates of HL60 cells were prepared for western blot analysis of RARa expression. b. HL60 cells were transfected by negative control (NC) or shRNA of RARa. Western blot analysis showed decreased RARa protein levels in both cell lines. $\mathbf{c}$ and $\mathbf{d}$ After infection of $72 \mathrm{~h}$, cells were treated with TPT for $24 \mathrm{~h}$. The apoptosis ratio of HL60 cells were detected by flow cytometry. *: Compared to TPT group, $\mathrm{p}<0.05$. The experiments were performed three times independently, and the error bars represent the SD around the mean. e After transfection of NC or siRNA of RARa, HL60 cells were treated with TPT for indicated minutes. Protein expression of $\mathrm{Y}$-H2AX was analyzed by western blot and densitometry quantification based on a-tublin expression. $\mathbf{f}$ After transfection of vector or RARa plasmid, HL60 cells were treated with TPT for indicated minutes and protein expression of $\mathrm{Y}-\mathrm{H} 2 \mathrm{AX}$ was analyzed by western blot

Figure 6a shows that the i.p. administration of ATRA at a dose of $5 \mathrm{mg} / \mathrm{kg}$ twice per week for nine days produced no significant difference in the mean RTV compared to the control group (mean RTV, ATRA vs. control: 12.5 vs. $17.1 ; \mathrm{P}>0.05)$. However, after a dosage of $2 \mathrm{mg} / \mathrm{kg}$ every week for nine days, TPT exerted a 

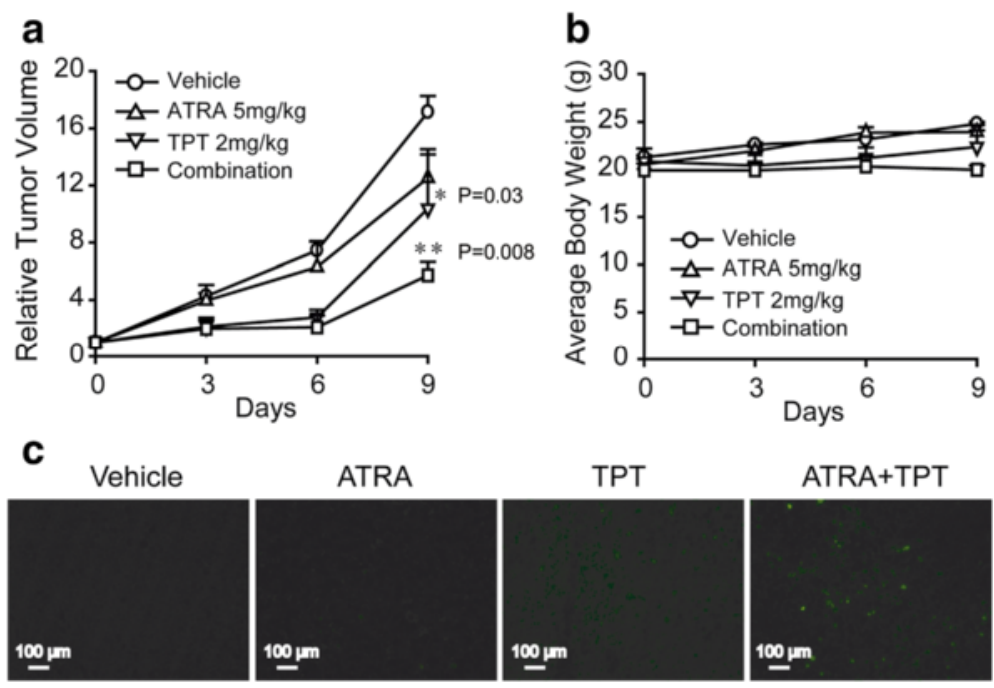

Fig. 6 Efficacy of TPT combined with ATRA treatment regimen in vivo. Mice transplanted with HL60 human xenografts were randomly divided into 4 groups and given injection of TPT (2 mg/ $\mathrm{kg}$, i.p.), ATRA (5 mg/ $\mathrm{kg}$, i.g.), combination, or vehicle for a period of 9 days. a Relative tumor volume was expressed as mean $\pm S D$ ( $n=3$ per group). $\mathbf{b}$ The average body weight of each group was expressed as mean $\pm S D(n=3$ per group). c Representative fluorescence images of TUNEL staining of tumor tissues collected from each group (magnification 100x)

moderate tumor growth inhibitory effect (mean RTV, TPT vs. control: 10.4 vs. $17.1 ; \mathrm{P}<0.05)$. As predicted, TPT plus ATRA caused marked tumor growth inhibition ( $\mathrm{T} / \mathrm{C}$ value: $33.3 \%)$ that was significantly greater than TPT (T/C value: $60.8 \%$ ) or ATRA treatment alone (T/C value: $73.1 \%$; mean $\mathrm{RTV}$, combination vs. TPT: 5.7 vs.10.4; $\mathrm{P}<0.01)$. Furthermore, compared to the initial body weights, combination treated mice showed no significant body weight loss in Fig. $6 \mathrm{~b}$.

The TUNEL assay was performed to evaluate the apoptosis-inducing abilities of the TPT and/or ATRA treatments. As shown in Fig. 6c, the number of TUNELpositive cells was significantly increased in the tumor tissues of combination-treated mice. All in vivo data were consistent with previous in vitro data and further supported that the synergistic antitumor efficacy of TPT and ATRA was a result of TPT aroused apoptosis.

\section{Discussion}

Acute myeloid leukemia is most often diagnosed in older people and children; more than $50 \%$ of patients with AML are over-60 and $15-20 \%$ are under 16 years old $[33,34]$. Chemotherapy is the only treatment option for the majority of AML patients and the most frequently used drugs are the deoxycytidine analog cytarabine and an anthoursacycline antibiotic, such as daunorubicin, idarubicin and the anthoursacenedione mitoxantrone [3]. However, multiple chemotherapy treatments are intolerable for children and older people with AML, therefore, new effective therapies with fewer side effects are urgently needed. In this study, we demonstrated that ATRA had a synergistic cytotoxicity with TPT for AML in vitro and in vivo closely related to DNA damageinduced apoptosis via RARa activity inhibition.

ATRA used in combination with chemotherapy has been shown to improve the outcome of patients with breast cancer, lung cancer, ovarian cancer and gastric cancer, and only presents a few side effects, which suggests a potential for clinical application in AML $[35,36]$. Previous studies in ovarian, gastric and melanoma cancer cells have shown that retinoic acid has synergistic effects on DNA damage with the drug cisplatin [37]. TPT is effective alone with cytotoxicity effects less than the doxorubicin (a classical AML drug) group (Additional file 1: Figure S1) or when combined with other drugs for AML, such as lapatinib, paclitaxel. However, TPT is limited by its toxicity $[14,16,17]$. ATRA was proposed as a potential drug to enhance the anticancer activity of TPT. We demonstrated that ATRA decreases the concentration that causes DNA damage from $200 \mathrm{nM}$ to $40 \mathrm{nM}$ TPT.

DNA integrity is critical for proper cellular function and proliferation in AML. Once a DNA lesion occurs, it leads to replication-associated DNA double-strand breaks (DSBs) that eventually cause apoptosis if the damaged DNA cannot be properly repaired [38]. Targeted therapies designed to induce apoptosis in leukemic cells are currently the most promising antileukemia strategies. We used flow cytometry analysis with PI staining, morphological evidence of apoptotic bodies, and immunoblotting to determine if the ratio of growth inhibition was induced by caspase-mediated apoptosis. The comet assay revealed that treatment with TPT and ATRA for one hour induces DNA SSBs in HL60 cells at high concentrations of TPT, although neither $40 \mathrm{nM}$ 
TPT or $1 \mu \mathrm{M}$ ATRA caused the SSBs first when using ATRA combined with TPT for one hour. Moreover, the DNA damage pathway and its transducers (Chk1, Chk2) were activated by TPT and ATRA at higher rates than TPT. Over time, the SSBs became DSBs and finally led to cell death by apoptosis.

ATRA binds to the retinoic acid receptor (RAR), RARalpha, RAR-beta, and RAR-gamma, which is bound to DNA as a heterodimer with the retinoid $\mathrm{X}$ receptor (RXR) in regions called retinoic acid response elements (RAREs), from there it affects gene transcription and modulates a wide variety of biological processes, such as apoptosis [31]. In our study, RAR $\alpha$ was knocked-down and the cells were susceptible to TPT, which increased the apoptosis rate. Therefore, we concluded that the existence of RAR $\alpha$ was unfavorable for programmed cell death. The combination regime showed that ATRA downregulates the protein level of RAR $\alpha$, and this might be the key for synergistic effects in this anticancer therapy. As a result, DNA damage can be induced more easily with ATRA. However, the influence of RAR $\alpha$ on TPT-induced DNA damage has not been explained, and the role of ATRA in the DNA damage pathway needs further exploration.

\section{Conclusion}

In summary, the combination of TPT and ATRA exhibited synergistic antitumor activity in vitro and in vivo demonstrated by a decreased tumor cell survival fraction, increased inhibition of tumor cell proliferation, significant activation of apoptosis cascades and an increased tumor growth inhibitory rate. Moreover, the synergistic activity was related to the suppression of RAR $\alpha$ proteins and caused single-strand DNA breaks, ultimately leading to cell death by generating double-stranded DNA breaks during DNA replication. Our results indicate that the combination therapy is a promising alternative to chemotherapeutic treatment for AML and should be further tested in clinical trials.

\section{Additional file}

Additional file 1: Figure S1. The TPT effect compared with doxorubicin (ADR). TPT induced cytotoxicity was Compared with ADR in AML cells. $4 \times$ 103 cells per well were cultured in 96-well plates and incubated with the indicated concentrations of TPT and ADR for $48 \mathrm{~h}$. Mean \pm SD from three independent experiments. (TIF $10371 \mathrm{~kb}$ )

\section{Competing interests}

The authors declare that they have no competing interests.

\section{Authors' contributions}

PHL, QJH and BY participated in the conception and design of the study. $L L$, ZFX, XMP, MC, GQL and HY acquire and analysis the data, PHL, JJS and LL constructed the manuscript. ZFX and XMP revise the manuscript critically. All authors read and approval the final manuscript.

\section{Acknowledgments}

This work was supported by gra

nts from National Natural Science Foundation of China No.

81473288 and Zhejiang Province Joint Construction Project (Grant number WSK2014-2-007).

Received: 10 August 2015 Accepted: 15 December 2015

Published online: 05 January 2016

\section{References}

1. Burnett A, Wetzler M, Lowenberg B. Therapeutic advances in acute myeloid leukemia. J Clin Oncol. 2011;29(5):487-94.

2. Lin TL, Levy MY. Acute myeloid leukemia: focus on novel therapeutic strategies. Clin Med Insights Oncol. 2012;6:205-17.

3. Tallman MS, Gilliland DG, Rowe JM. Drug therapy for acute myeloid leukemia. Blood. 2005;106(4):1154-63.

4. Pinkel D. Bone marrow transplant in acute myeloid leukemia. J Clin Oncol. 1994;12(8):1737.

5. Nardi V, Winkfield KM, Ok CY, Niemierko A, Kluk MJ, Attar EC, et al. Acute myeloid leukemia and myelodysplastic syndromes after radiation therapy are similar to de novo disease and differ from other therapy-related myeloid neoplasms. J Clin Oncol. 2012;30(19):2340-7.

6. Buchner T, Urbanitz D, Ruhl H, Fischer J, Kuse R. Role of chemotherapy for AML in remission. Lancet. 1985;1(8439):1224-5.

7. Kushner BH, Cheung NK, Kramer K, Dunkel IJ, Calleja E, Boulad F. Topotecan combined with myeloablative doses of thiotepa and carboplatin for neuroblastoma, brain tumors, and other poor-risk solid tumors in children and young adults. Bone Marrow Transplant. 2001;28(6):551-6.

8. Radhakrishnan K, Lee A, Harrison LA, Morris E, Shen V, Gates L, et al. A novel trial of topotecan, ifosfamide, and carboplatin (TIC) in children with recurrent solid tumors. Pediatr Blood Cancer. 2014. doi: 10.1002/pbc.25309. [Epub ahead of print].

9. Zhang FL, Wang P, Liu YH, Liu LB, Liu XB, Li Z, et al. Topoisomerase I inhibitors, shikonin and topotecan, inhibit growth and induce apoptosis of glioma cells and glioma stem cells. PloS ONE. 2013;8(11):e81815.

10. Kim MK, James J, Annunziata CM. Topotecan synergizes with CHEK1 (CHK1) inhibitor to induce apoptosis in ovarian cancer cells. BMC Cancer. 2015;15:196.

11. Zhang YW, Regairaz M, Seiler JA, Agama KK, Doroshow JH, Pommier Y. Poly(ADP-ribose) polymerase and XPF-ERCC1 participate in distinct pathways for the repair of topoisomerase l-induced DNA damage in mammalian cells. Nucleic Acids Res. 2011;39(9):3607-20.

12. Creemers GJ, Lund B, Verweij J. Topoisomerase I inhibitors: topotecan and irenotecan. Cancer Treat Rev. 1994;20(1):73-96.

13. Bolanos-Meade J, Guo C, Gojo I, Karp JE. A phase II study of timed sequential therapy of acute myelogenous leukemia (AML) for patients over the age of 60: two cycle timed sequential therapy with topotecan, ara-C and mitoxantrone in adults with poor-risk AML. Leukemia Res. 2004;28(6):571-7.

14. Inaba H, Stewart CF, Crews KR, Yang S, Pounds S, Pui CH, et al. Combination of cladribine plus topotecan for recurrent or refractory pediatric acute myeloid leukemia. Cancer. 2010;116(1):98-105.

15. Leoni F, Ciolli S, Nozzoli C, Santini V, Fanci R, Rossi Ferrini P. Fludarabine, cytarabine and topotecan (FLAT) as induction therapy for acute myeloid leukemia in the elderly: a preliminary report. Haematologica. 2001;86(1):104.

16. Prebet $T$, Jean E, Autret A, Charbonnier A, Rey J, Etienne A, et al. Combination of cytarabine and topotecan in patients treated for acute myeloid leukemia with persistent disease after frontline induction. Leuk Lymphoma. 2012;53(11):2186-91.

17. Vey N, Kantarjian H, Beran M, O'Brien S, Cortes J, Koller C, et al. Combination of topotecan with cytarabine or etoposide in patients with refractory or relapsed acute myeloid leukemia: results of a randomized phase I/II study. Invest New Drugs. 1999;17(1):89-95.

18. Lu Y, Li F, Mu Q, Meng H, Qian W, Tong H, et al. The clinical efficacy of all-trans retinoic acid plus arsenic trioxide in 177 newly diagnosed acute promyelocytic leukemia patients. Zhonghua xue ye xue za zhi. 2015;36(5):372-7.

19. Mandelli F, Diverio D, Avvisati G, Luciano A, Barbui T, Bernasconi C, et al. Molecular remission in PML/RAR alpha-positive acute promyelocytic leukemia by combined all-trans retinoic acid and idarubicin (AIDA) therapy. Gruppo Italiano-Malattie Ematologiche Maligne dell'Adulto and 
Associazione Italiana di Ematologia ed Oncologia Pediatrica Cooperative Groups. Blood. 1997;90(3):1014-21.

20. Huang M, Gao H, Chen Y, Zhu H, Cai Y, Zhang X, et al. Chimmitecan, a novel 9-substituted camptothecin, with improved anticancer pharmacologic profiles in vitro and in vivo. Clin Cancer Res. 2007;13(4):1298-307.

21. Zheng L, Yang W, Zhang C, Ding WJ, Zhu H, Lin NM, et al. GDC-0941 sensitizes breast cancer to ABT-737 in vitro and in vivo through promoting the degradation of Mcl-1. Cancer Lett. 2011;309(1):27-36.

22. Sabine VS, Faratian D, Kirkegaard-Clausen T, Bartlett JM. Validation of activated caspase-3 antibody staining as a marker of apoptosis in breast cancer. Histopathology. 2012;60(2):369-71.

23. Li G, Zhou J, Budhraja A, Hu X, Chen Y, Cheng Q, et al. Mitochondrial translocation and interaction of cofilin and Drp1 are required for erucininduced mitochondrial fission and apoptosis. Oncotarget. 2015;6(3):1834-49.

24. Pisani F, Del Poeta G, Aronica G, Venditti A, Caravita T, Amadori S. In vitro down-regulation of bcl-2 expression by all-trans retinoic acid in AML blasts. Annals of hematology. 1997;75(4):145-7.

25. Lee H, Chin H, Kim K, Lee D. ERBB3 knockdown induces cell cycle arrest and activation of Bak and Bax-dependent apoptosis in colon cancer cells. Oncotarget. 2014;5(13):5138-52.

26. Cortes-Gutierrez El, Hernandez-Garza F, Garcia-Perez JO, Davila-Rodriguez MI, Aguado-Barrera ME, Cerda-Flores RM. Evaluation of DNA single and double strand breaks in women with cervical neoplasia based on alkaline and neutral comet assay techniques. J Biomedicine Biotechnol. 2012;2012:385245.

27. Fracasso ME, Doria D, Carrieri M, Bartolucci GB, Quintavalle S, De Rosa E. DNA single- and double-strand breaks by alkaline- and immuno-comet assay in lymphocytes of workers exposed to styrene. Toxicol Lett. 2009;185(1):9-15

28. Rogakou EP, Pilch DR, Orr AH, Ivanova VS, Bonner WM. DNA double-stranded breaks induce histone H2AX phosphorylation on serine 139. J Biol Chem. 1998;273(10):5858-68.

29. Hsiang YH, Lihou MG, Liu LF. Arrest of replication forks by drug-stabilized topoisomerase I-DNA cleavable complexes as a mechanism of cell killing by camptothecin. Cancer Res. 1989;49(18):5077-82.

30. Chen Y, Sanchez Y. Chk1 in the DNA damage response: conserved roles from yeasts to mammals. DNA Repair. 2004;3(8-9):1025-32.

31. Chertow BS, Goking NQ, Driscoll HK, Primerano DA, Matthews KA. Effects of all-trans-retinoic acid (ATRA) and retinoic acid receptor (RAR) expression on secretion, growth, and apoptosis of insulin-secreting RINm5F cells. Pancreas. 1997;15(2):122-31.

32. Fang $Y$, Zhou $X$, Lin $M$, Ying $M$, Luo $P$, Zhu $D$, et al. Inhibition of all-trans-retinoic acid-induced proteasome activation potentiates the differentiating effect of retinoid in acute myeloid leukemia cells. Mol Carcinog. 2011;50(1):24-35.

33. Laubach J, Rao AV. Current and emerging strategies for the management of acute myeloid leukemia in the elderly. Oncologist. 2008;13(10):1097-108.

34. Pinkel D. Treatment of children with acute myeloid leukemia. Blood. 2001;97(11):3673. author reply 3674-3675.

35. Di Noto R, Lo Pardo C, Schiavone EM, Ferrara F, Manzo C, Vacca C, et al. All-trans retinoic acid (ATRA) and the regulation of adhesion molecules in acute myeloid leukemia. Leuk Lymphoma. 1996;21(3-4):201-9.

36. Hoffman E, Mielicki WP. All-trans retinoic acid (ATRA) in prevention and cancer therapy. Postepy Hig Med Dosw (Online). 2010;64:284-90.

37. Caliaro MJ, Vitaux P, Lafon C, Lochon I, Nehme A, Valette A, et al. Multifactorial mechanism for the potentiation of cisplatin (CDDP) cytotoxicity by all-trans retinoic acid (ATRA) in human ovarian carcinoma cell lines. Br J Cancer. 1997;75(3):333-40.

38. Kumar S, Yedjou CG, Tchounwou PB. Arsenic trioxide induces oxidative stress, DNA damage, and mitochondrial pathway of apoptosis in human leukemia (HL-60) cells. J Exp Clin Cancer Res. 2014;33:42.

\section{Submit your next manuscript to BioMed Central and we will help you at every step:}

- We accept pre-submission inquiries

- Our selector tool helps you to find the most relevant journal

- We provide round the clock customer support

- Convenient online submission

- Thorough peer review

- Inclusion in PubMed and all major indexing services

- Maximum visibility for your research

Submit your manuscript at www.biomedcentral.com/submit
() BioMed Central 